\title{
Comparative molecular analysis of chemolithoautotrophic bacterial diversity and community structure from coastal saline soils, Gujarat, India
}

Basit Yousuf, Payal Sanadhya, Jitendra Keshri and Bhavanath Jha*

\begin{abstract}
Background: Soils harbour high diversity of obligate as well as facultative chemolithoautotrophic bacteria that contribute significantly to $\mathrm{CO}_{2}$ dynamics in soil. In this study, we used culture dependent and independent methods to assess the community structure and diversity of chemolithoautotrophs in agricultural and coastal barren saline soils (low and high salinity). We studied the composition and distribution of chemolithoautotrophs by means of functional marker gene cbbl encoding large subunit of ribulose-1,5-bisphosphate carboxylase/oxygenase and a phylogenetic marker $16 S$ rRNA gene. The cbbL form IA and IC genes associated with carbon fixation were analyzed to gain insight into metabolic potential of chemolithoautotrophs in three soil types of coastal ecosystems which had a very different salt load and sulphur content.
\end{abstract}

Results: In cbbL libraries, the cbbL form IA was retrieved only from high saline soil whereas form IC was found in all three soil types. The form IC cbbL was also amplified from bacterial isolates obtained from all soil types. A number of novel monophyletic lineages affiliated with form IA and IC phylogenetic trees were found. These were distantly related to the known cbbL sequences from agroecosystem, volcanic ashes and marine environments. In 16S rRNA clone libraries, the agricultural soil was dominated by chemolithoautotrophs (Betaproteobacteria) whereas photoautotrophic Chloroflexi and sulphide oxidizers dominated saline ecosystems. Environmental specificity was apparently visible at both higher taxonomic levels (phylum) and lower taxonomic levels (genus and species). The differentiation in community structure and diversity in three soil ecosystems was supported by LIBSHUFF $(P=0.001)$ and UniFrac.

Conclusion: This study may provide fundamentally new insights into the role of chemolithoautotrophic and photoautotrophic bacterial diversity in biochemical carbon cycling in barren saline soils. The bacterial communities varied greatly among the three sites, probably because of differences in salinity, carbon and sulphur contents. The $c b b L$ form IA-containing sulphide-oxidizing chemolithotrophs were found only in high saline soil clone library, thus giving the indication of sulphide availability in this soil ecosystem. This is the first comparative study of the community structure and diversity of chemolithoautotrophic bacteria in coastal agricultural and saline barren soils using functional (cbbl) and phylogenetic (16S rDNA) marker genes.

Keywords: $c b b L$, Clone libraries, 165 rRNA gene, RuBisCO, Barren soil

\footnotetext{
*Correspondence: bjha@csmcriorg

Discipline of Marine Biotechnology and Ecology, CSIR - Central Salt and

Marine Chemicals Research Institute, G.B Marg, Bhavnagar 364021, Gujarat,

India
}

\section{Biomed Central}

(c) 2012 Yousuf et al.; licensee BioMed Central Ltd. This is an Open Access article distributed under the terms of the Creative Commons Attribution License (http://creativecommons.org/licenses/by/2.0), which permits unrestricted use, distribution, and reproduction in any medium, provided the original work is properly cited. 


\section{Background}

Chemolithoautotrophic bacteria utilize inorganic compounds as electron donors for growth. They are subdivided into two main groups based on their electron donors: Obligate lithotrophs including hydrogen-, sulphide-, sulphur-, metal-, ammonia-, nitrite- oxidizing bacteria and facultative lithotrophs such as $\mathrm{CO}$-oxidizing bacteria [1]. Chemolithoautotrophic soil microorganisms contribute significantly in sequestration of the green house gas $\mathrm{CO}_{2}$ which helps in climate sustainability and assimilate $\mathrm{CO}_{2}$ mainly by Calvin-Benson-Bassham (CBB) pathway. However, some chemolithotrophs such as Epsilonproteobacteria have been reported to use the reductive tricarboxylic acid cycle [2]. The crucial enzyme of the CBB cycle is ribulose-1,5-bisphosphate carboxylase/ oxygenase (RuBisCO) which occurs in four forms [3]. Form I RuBisCO found in higher plants, algae, Cyanobacteria and chemolithoautotrophs, is by far the most abundant enzyme in the world [4]. It is a bifunctional enzyme capable of fixing either $\mathrm{CO}_{2}$ or $\mathrm{O}_{2}$. It is commonly found in cytoplasm, but a number of bacteria package much of the enzyme into polyhedral organelles, the carboxysomes. These carboxysomes enhance $\mathrm{CO}_{2}$ fixation. This enzyme is climate resilient and consists of 8 large and 8 small subunits. Form I is considered to be evolved from form II, which consists of only large subunits [5]. Archaea contain a separate class of RuBisCO termed as form III [6,7]. Form IV has been found in $\mathrm{Ba}$ cillus subtilis [8], Chlorobium tepidum [9] and Archaeoglobus fulgidus [10]. Form III and IV are referred as RuBisCO like proteins.

The large subunit of form I RuBisCO is encoded by $c b b L$-gene [11]. The form I RuBisCO is essentially found in two major forms, green like and red like, which show differences in their amino acid compositions [12]. The green like RuBisCO is divided into two types, IA and IB. Form IA is found in Alpha-, Beta- and Gammaproteobacteria and is phylogenetically allied to form IB which occurs in the chloroplasts of terrestrial plants, green algae and Cyanobacteria [12]. The red like RuBisCO is also divided into two relatively close forms, IC and ID. Form IC is found in Alpha- and Betaproteobacteria and many non green algae carry form ID [12]. Form IA genes are harboured by obligate and some facultative chemolithotrophs which utilize either inorganic or organic substrates [1]. However, there are some exceptions such as Hydrogenophaga pseudoflava, oxidizing CO and hydrogen but does not oxidize reduced sulphur species [13]. In contrast, form IC $c b b L$ occurs in manganese-, $\mathrm{CO}$ - and hydrogen-oxidizing facultative chemolithotrophic bacteria that potentially use heterotrophic substrate as carbon sources. A distinct form of IC $c b b L$ sequences are also reported in a group of ammoniaoxidizing Nitrosospira species [14].
The phylogenetic relationships of specific functional bacterial groups by use of $16 \mathrm{~S}$ rRNA gene and a corresponding functional marker gene such as nifH, amo $A$ and $\operatorname{dsr} A B$ have been previously studied [15-18]. In this study we used $16 \mathrm{~S}$ rRNA gene and a functional marker gene $c b b L$ for determining phylogenetic relationships of chemolithoautotrophs. The phylogenetic affiliations based on $c b b L$ gene are incongruent with 16S rRNA gene phylogeny due to horizontal gene transfer of the $c b b L$-gene. Nevertheless, the $c b b L$-gene seems to be useful for studying evolution and diversity of autotrophic organisms. This discrepancy in nature of RuBisCO phylogeny is only evident at higher taxonomic levels and has negligible apparent affect at lower taxonomic levels [19]. To date, molecular ecological studies based on RuBisCO genes are mostly restricted to aquatic systems $[17,20-23]$ with relatively few analysis devoted to chemolithotrophs in soil $[14,24]$ and fewer from extreme terrestrial systems $[25,26]$. Thus to gain an insight into specific biochemical pathways and evolutionary relationships, $c b b L$ and 16S rRNA gene sequences were studied together in chemolithoautotrophs from coastal saline ecosystem.

In this study we report the diversity, community structure and phylogenetic affiliation of chemolithoautotrophic bacteria in two contrasting soil ecosystems i.e. agricultural soil and coastal barren saline soils using both culture dependent and independent methods. DNA was extracted from bacterial isolates as well as soil samples, $c b b L$ (form IA \& form IC) and 16S rRNA gene clone libraries were constructed and analyzed. The $c b b L$ form IC sequences were most diverse in agricultural system while form IA was found only in one saline sample (SS2) which reflects the possible availability of sulphide in saline soil. This is the first comprehensive study on chemolithoautotrophs from coastal saline soil.

\section{Results}

The three soils showed variations in water content, $\mathrm{pH}$, salinity, organic carbon, nitrogen and sulphur contents (Table 1). The agricultural soil (AS) had electrolytic conductivity (EC) of $0.12 \mathrm{dS} \mathrm{m}^{-1}$ and $\mathrm{pH} 7.09$ whereas the

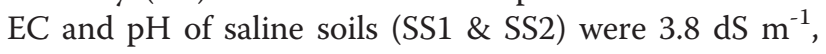

Table 1 Physico-chemical properties of agricultural soil (AS) and saline soils (SS1 \& SS2)

\begin{tabular}{lccccccc}
\hline Site & EC $\left(\mathbf{d S ~ m}^{-1}\right)^{\mathbf{1}}$ & pH & TC $^{2}(\%)$ & TIC $^{\mathbf{3}}(\%)$ & TOC $^{\mathbf{4}}(\%)$ & TN $^{5}(\%)$ & $\mathbf{S}^{\mathbf{6}}(\%)$ \\
\hline AS & 0.12 & 7.09 & 2.65 & 1.6 & 1.04 & 0.14 & 0.016 \\
SS1 & 3.8 & 8.3 & 1.27 & 0.83 & 0.44 & 0.09 & 0.11 \\
SS2 & 7.1 & 8.0 & 1.38 & 0.78 & 0.61 & 0.09 & 0.28
\end{tabular}

\footnotetext{
${ }^{1}$ Electrolytic conductivity.

2 Total carbon.

${ }^{3}$ Total inorganic carbon.

${ }^{4}$ Total organic carbon.

${ }^{5}$ Total nitrogen.

${ }^{6}$ Sulphur.
} 
8.3 and $7.1 \mathrm{dS} \mathrm{m}^{-1}$, and $\mathrm{pH}$ 8.0. Total carbon level varied with high content in agricultural soil $(2.65 \%)$ and low content in saline soils SS1 (1.27\%) and SS2 (1.38\%). The nitrogen content was high in agricultural soil while sulphur concentration was high in saline soil SS2. DNA extraction from soil samples, PCR amplification and gene library construction were carried out in duplicate (per site). A comparison of sequences from each site (within transects) revealed that the libraries displayed 90-93\% similarity with each other. This was well supported by weighted UniFrac environmental clustering analysis which indicated that the bacterial communities within sites were not significantly differentiated (UniFrac $P=0.5$ for AS, 0.9 for SS1 and 0.9 for SS2) in both $c b b L$ and $16 \mathrm{~S}$ rRNA clone libraries. One of the clone libraries from each sample has been further analyzed.

\section{CbbL clone libraries (Form IC \& IA)}

$C b b L$ clone sequences were grouped into OTUs based on a cut-off of $95 \%$ sequence similarity. Totals of 141, 99 and 103 form IC $c b b L$ clone sequences were obtained from agricultural (AS) and two saline (SS1 \& SS2) soils and termed BS, HS, and RS respectively. Overall, the red like clone sequences yielded 58, 32 and 40 unique phylotypes for AS, SS1 \& SS2 clone libraries respectively. Heatmap (Additional file 1: Figure S1) generated by Mothur program depicts the relative abundance of these phylotypes within respective clone libraries. In spite of repeated attempts to amplify and clone PCR products, only 28 partial form IA clone sequences were obtained from the saline soil (SS2), termed "RG clones", and could be grouped into 8 OTUs (Figure 1). Comparisons with the NCBI database by BLAST searches revealed that these OTUs were only distantly related to the known green-like $c b b L$ sequences (Figure 1).

\section{Phylogenetic affiliation of RuBisCO genes}

The phylogenetic trees were constructed by neighbour joining method using Jukes-Cantor correction. A composite phylogenetic tree was generated from selected nucleotide sequences of form IC $c b b L$ genes from all three soil samples and bacterial isolates (Figure 2). Separate trees for AS and SS1 \& SS2 were also generated from aligned nucleotide sequences of form IC $c b b L$ genes (Additional file 2: Figure S2a and Additional file 3: Figure S2b). In the composite tree, majority of the phylotypes $(60 \%)$ from different soil types did not cluster close to the $c b b L$ sequences of known autotrophs. The sequences of cluster 2 (4 OTUs), cluster 6 (12 OTUs), cluster 7 (5 OTUs, 7 cultured isolates), cluster 8 (6 OTUs), cluster 13 (8 OTUs) and cluster 14 (4 OTUs) formed novel monophyletic groups not affiliated to known $c b b L$ gene containing bacteria. Some of the clone sequences clustered with $c b b L$ sequences from known lithotrophs. OTUs from AS soil were grouped into one site specific cluster (cluster 8 ). The phylotypes from saline soils were closely clustered within cluster 3 , cluster 6 , cluster 7 , cluster 14 and cluster 15 . The remaining clusters $(1,2,4,5,9,10,11,12$ \& 13) displayed random distribution of agricultural and saline soil OTUs, containing sequences from all three soil samples. The largest clade of the composite tree, cluster 11 (24 OTUs, 50 clones) comprised sequences having ubiquitous distribution in all three clone libraries (Figure 2), and was affiliated to Rhizobium leguminosarum.

In the phylogenetic tree constructed from the phylotypes of agroecosystem clone library, fifty eight OTUs could be classified into nine clusters with the largest clade (cluster 1) constituting $28 \%$ of clone library. Cluster 1 (14 OTUs, 40 sequences), cluster $2(8,17)$ cluster 3 $(8,12)$, cluster $4(10,17)$, cluster $5(1,1)$, cluster $6(5$, $17)$, cluster $7(6,15)$, cluster $8(4,10)$ and cluster $9(5$ cultured isolates) were grouped together in AS phylogenetic tree (Additional file 2: Figure S2a). Cluster 3 and 4 included reference sequence from Bradyrhizobium japonicum, Rhizobium leguminosarum, Alcaligenes, Pelomonas, Paracoccus and Ochrobactrum anthropi. The sequences of cluster 1 and 8 formed novel monophyletic groups without showing any affiliation with known $c b b L$ gene containing organisms and constitute the majority of clones. The phylotype BS146 and cluster 9 (cultured isolates) constitute a branching lineage directly originating from the root not allied with any known organism. Two phylotypes BS203 and BS78 were related to Sulfobacillus acidophilus and formed a separate cluster with Mycobacterium.

In the phylogenetic tree constructed from the phylotypes of saline soil clone libraries, seventy two OTUs could be assigned to eight clusters, largest cluster being clade 1 constituting 17\% of clone libraries (Additional file 3: Figure S2b). The OTUs were phylogenetically placed with different groups of autotrophic Alpha-, Beta- and Gammaproteobacteria which are abundant in soils. Most of the OTUs were not closely affiliated $(<93 \%$ nucleotide similarity) with RuBisCO sequences in the database, however, some of them were clearly related to a variety of clone sequences reported from differently managed agricultural systems, volcanic deposits, marine environments, contaminated aquifers, deltaic mobile sediments, arid and grassland soils. In the phylogenetic tree from saline soils, OTUs from cluster 3 (9 OTUs and 32 clones), cluster $5(12,32)$, cluster $6(3,13)$, cluster 7 $(6,15)$ and cluster $8(2,6)$ grouped with $c b b L$ sequences of known cultured organisms like Rhodopseudomonas palustris, Oligotropha carboxidovorans, Nitrosospira, Rhizobium leguminosarum, Salinisphaera, Alcaligenes, Pelomonas, Paracoccus, Rhodobacter, Agrobacterium tumefaciens, Sinorhizobium fredii and Ochrobactrum 


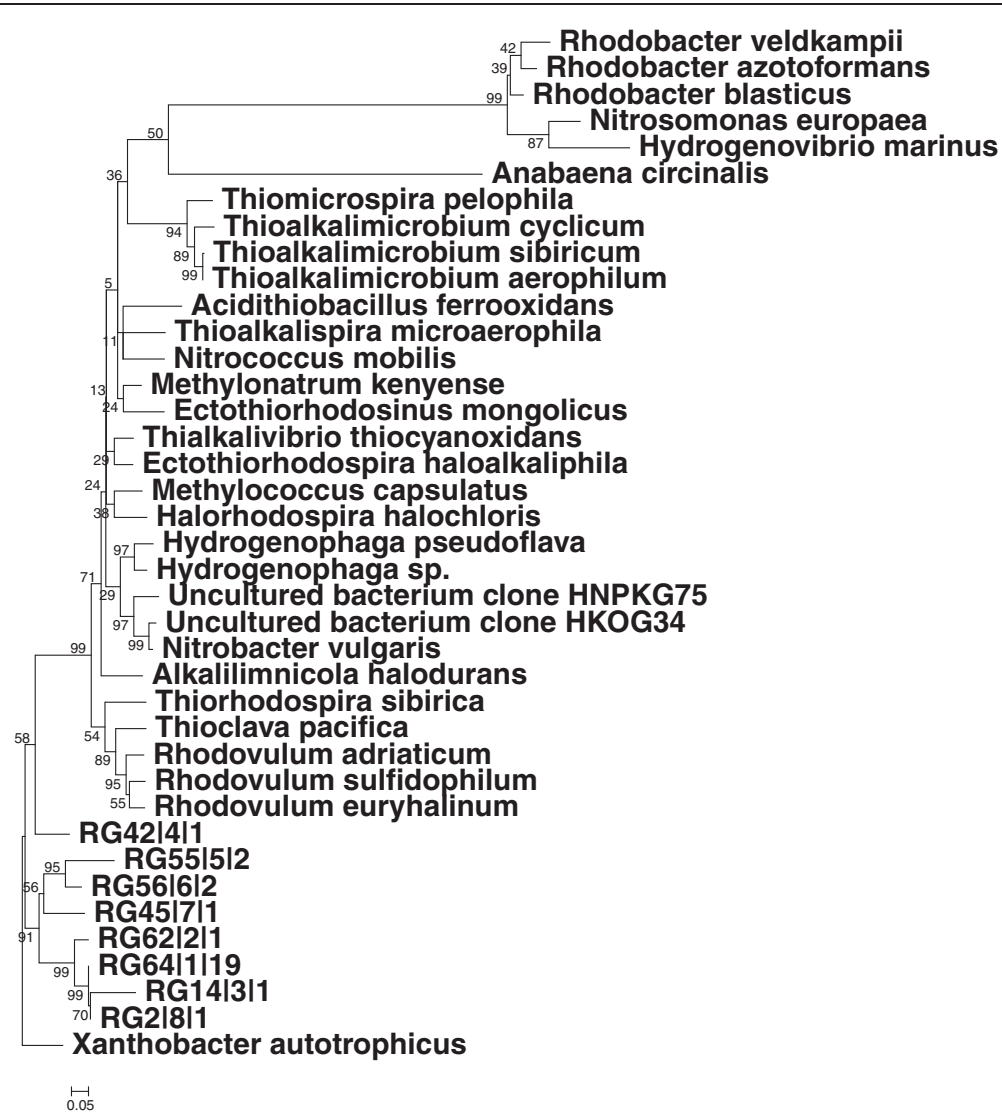

Figure 1 Phylogenetic analysis of green like $c b b L$ clones. Neighbour-joining tree (Jukes-Cantor correction) was constructed from saline soil (SS2) clone library partial cbbL (form IA) nucleic acid sequences (phylotypes) with closely related cbbL-gene sequences from known organisms and environmental clones. Clone sequences of form IA cbbL sequence are coded as 'RG'. One representative phylotype is shown followed by phylotype number and the number of clones within each phylotype is shown at the end. One thousand bootstrap analyses were performed and percentages are shown at nodes. The scale bar indicates 0.05 substitutions per site. The red-like cbbl sequence of Xanthobacter autotrophicus was used as outgroup for tree calculations.

anthropi (79-88\%). The $c b b L$ sequences in the cluster 4 $(8,20)$ were grouped with Aurantimonas bacterium (4 OTUs), Methylocapsa acidiphila (one OTU), Bradyrhizobium japonicum (one OTU) and Azospirillum lipoferum (one OTU). Some sequences in the cluster 5 displayed sequence homology with Nitrosospira. Phylotype HS154 was distantly related with Sulfobacillus acidophilus and Mycobacterium. Cluster 1 (12, 35, 2 cultured isolates) showed a high intra cluster similarity not affiliated with any other known RuBisCO sequence and formed a monophyletic lineage with $c b b L$ sequences of the cultured isolates (HSC14, RSC22) obtained from these soil samples. The phylotype R13 from saline soil constituted a distinct branching lineage not affiliated with any known $c b b L$ containing cultured representative.

The form IA $c b b L$ genes were amplified only from high saline soil (SS2). The phylogenetic analysis (Figure 1) revealed that the 8 phylotypes (28 clones) were not closely associated with known sulphide, ammonia oxidizers or other taxa and formed one separate monophyletic cluster. Furthermore, the form IA clone sequence RG42 was divergent from other form IA gene sequences.

\section{S rRNA clone library and phylogenetic analysis}

Total 329 16S rRNA gene clone sequences were retrieved from three soil samples. The RDP classifier was used to assign $16 \mathrm{~S}$ rRNA gene sequences to the phylogenetic groups (Figure 3). Totally 227 OTUs were identified among the 329 clones in the combined data set. Comparative abundance of these OTUs was illustrated by heatmap (Additional file 1: Figure S1) generated by Mothur. A total of 147 clone sequences were analyzed from the agricultural soil (AS), which generated 109 unique OTUs that grouped within ten bacterial phylaProteobacteria (Alpha, Beta, Gamma, and Delta), Acidobacteria, Actinobacteria, Bacteroidetes, Chloroflexi, Cyanobacteria, Firmicutes, Gemmatimonadetes, Nitrospira and Planctomycetes. A total of 97 and 85 gene sequences were analyzed from saline soils (SS1 \& SS2) which generated 55 and 63 unique OTUs respectively. 


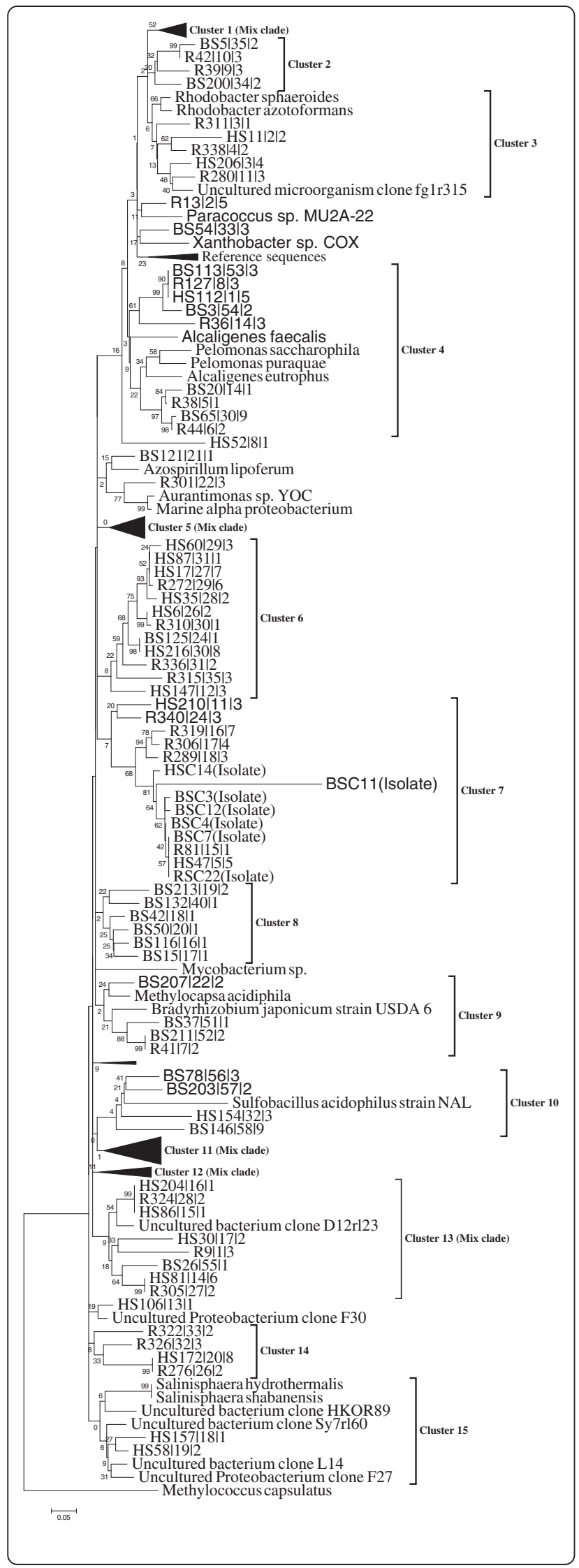

Figure 2 Phylogenetic analysis of red like cbbL clones. A composite neighbour joining tree (Jukes-Cantor correction) was constructed from aligned nucleotide sequences (phylotypes) of form IC cbbL-gene obtained from agricultural soil 'AS' and barren saline soils 'SS1 \& SS2' with closely related cbbL-gene sequences from known organisms and environmental clones. Bootstrap values are shown as percentages of 1000 bootstrap replicates. The bar indicates 5\% estimated sequence divergence. One representative phylotype is shown followed by phylotype number and the number of clones within each phylotype is shown at the end. Clone sequences from this study are coded as 'BS' (AS), 'HS' (SS1) and ' $R$ ' (SS2). The CbbL-gene sequences of the isolates from this study are denoted as 'BSC', 'HSC' and 'RSC' from AS, SS1 and SS2 respectively. The green-like cbbl-gene sequence of Methylococcus capsulatus was used as outgroup for tree calculations.

These OTUs grouped into different bacterial phyla as described above except Cyanobacteria and Nitrospira. The phylogenetic trees showing the taxonomic assignment of phylotypes to different bacterial groups were constructed from the three soil clone libraries (data not shown).

The detailed affiliation of different phylotypes with their closest neighbour in database is presented in Additional file 4: Table S1. The majority of phylotypes that belong to Alphaproteobacteria were from AS clone library. These OTUs were related (85-99\%) to Rhizobiales, Sphingomonadales and Rhodospirillales while six OTUs from SS1 \& SS2 libraries showed affiliation (89-99\%) to Rhodobacterales, Rhizobiales and Rhodospirillales. A cluster of 25 sequences from AS clone library (7 OTUs), which contributes $58.7 \%$ of the total AS Betaproteobacterial population were related (87-99\%) to Limnobacter thiooxidans from family Burkholderiaceae, formed one of its largest cluster. The only SS1 OTU HSS79 showed 97\% similarity to uncultured Betaproteobacteria whereas no OTU was observed in SS2 clone library.

The 22 OTUs (4 from AS and 18 from SS1 \& SS2 clone libraries) were related to different species of uncultured Gammaproteobacteria. Most of the SS1 \& SS2 clone sequences were related to cultured bacteria like Salinisphaeraceae bacterium, Methylohalomonas lacus, sulphur-oxidizing bacterium and Marinobacter species. The presence of sulphur-oxidizing and Marinobacter bacteria in saline soils may suggest the presence of sulphur in these saline environments. These saline soils indeed contain sulphur (Table 1). Deltaproteobacterial OTUs from SS1 \& SS2 clone libraries formed a tight cluster with deep sea bacterium, uncultured Deltaproteobacteria and Marinobacterium.

OTUs belonging to photoautotrophic Cyanobacteria and chemoautotrophic nitrifying Nitrospira were found only in AS clone library. Two phylotypes BSS159 and BSS49 were related (91\%) to Cyanobacteria and 


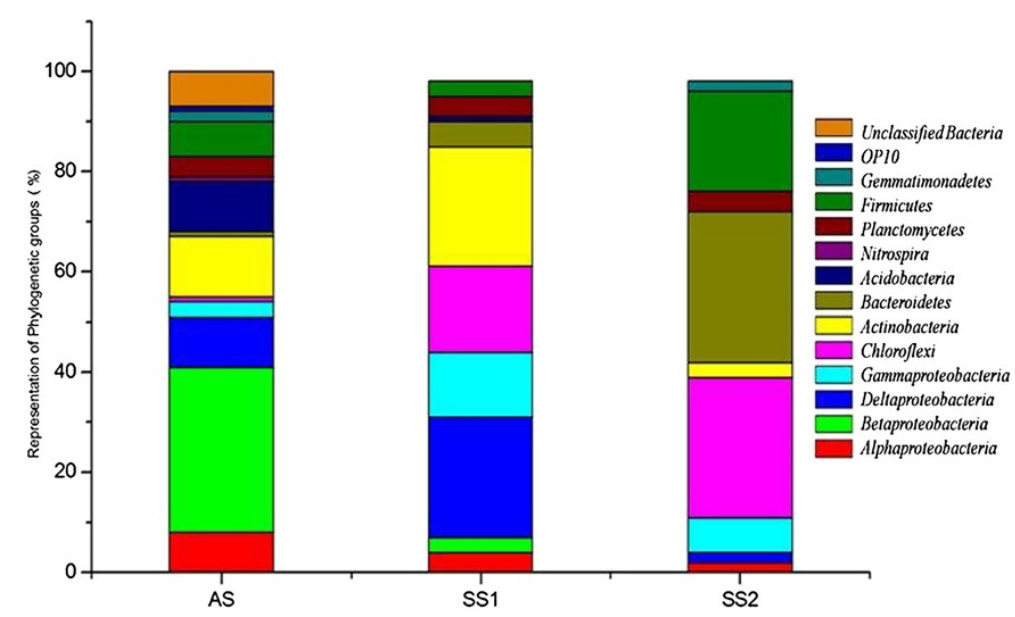

Figure 3 Taxonomic distribution of different bacterial phylogenetic groups in agricultural soil (AS) and saline soils (SS1, SS2). Analysis of amplified 16S rRNA gene sequences was done in comparison with the RDP II database (match length >1200 nucleotides). The percentages of the phylogenetically classified sequences are plotted on y-axis.

uncultured Nitrospira, respectively and more may be present as rarefaction curves did not reached saturation, although started to level off. The photoautotrophic Chloroflexi related sequences were mostly from SS1 \& SS2 clone libraries within the families Caldilineaceae, Sphaerobacteraceae and Anaerolineaceae. One OTU RS187 had 88\% homology with Sphaerobacter thermophilus, no other OTUs were more than $91 \%$ similar to that of any described organism (Additional file 4: Table S1). There were only two OTUs from AS clone library which showed affiliation $(>92 \%)$ to uncultured Chloroflexi. van der Meer et al. (2005) [27] suggested that Cyanobacteria and Chloroflexi utilize different spectra of light, and $\mathrm{CO}_{2}$ from the atmosphere for photosynthesis.

Firmicutes related sequences were found mostly in AS and SS2 clone library. One phylotype RS190 was affiliated with Bacillus polygoni (95\%) a moderately halophilic, non-motile, obligate alkaliphile isolated from indigo balls. Two OTUs RS39 and RS147 showed close relationship with Halanaerobiales from which one phylotype was distantly related (84\%) to Halothermothrix orenii a halophilic, thermophilic fermentative anaerobic bacterium [28].

The Bacteroidetes sequences were abundant in the SS2 clone library (Additional file 4: Table S1). Two phylotypes (RS23, RS17) were related to Salinimicrobium catena isolated from sediments of oil fields in the South China Sea [29] within Flavobacteriaceae. The Acidobacteria group was dominant in the AS clone library and the sequences were related (88-99\%) to uncultured Solibacter isolated from hydrocarbon contaminated soils [30], and uncultured Acidobacteria isolated from the heavy metal contaminated soils [31]. No phylotype from SS2 was found related to this group. Planctomycetes group was represented by twelve OTUs (13 sequences), four from each soil sample. The OTUs from SS1 \& SS2 clone libraries were related to uncultured marine bacteria and Planctomyces maris (Additional file 4: Table S1).

The Actinobacterial clones from AS clone library were related (93-99\%) to Micromonospora, Arthrobacter globiformis, Streptomyces and Rubrobacter radiotolerans. Eleven OTUs from SS1 \& SS2 clone libraries clustered with uncultured Actinobacteria, Amycolatopsis and Nitriliruptor alkaliphilus, a haloalkaliphilic actinobacterium from soda lake capable of growth on aliphatic nitriles [32]. Overall eight OTUs, six from AS and two from SS2 clone library were related (89-95\%) to the uncultured Gemmatimonadetes bacterium. No OTU was found affiliated to the Gemmatimonadetes group in SS1 clone library. Three OTUs from AS clone library were related to the uncultured phylum OP10.

\section{Phylogenetic analysis of $c b b L$ positive bacterial isolates}

From a total of 22 bacterial isolates seven were positive for form IC $c b b L$ genes. The positive isolates were analyzed for further study. The $c b b L$-gene sequences of the isolates from this study were denoted as 'BSC, 'HSC' and 'RSC' from AS, SS1 and SS2 soil samples, respectively. The nucleotide similarities of $c b b L$ sequences retrieved from the bacterial isolates were distantly related (77-85\%) to known $c b b L$ sequences. The $16 \mathrm{~S}$ rRNA gene sequences of the isolates from this study were denoted as 'BSCS' (AS), 'HSCS' (SS1) and 'RSCS' (SS2). A neighbour joining tree (Additional file 5: Figure S3) was constructed from $16 \mathrm{~S}$ rRNA gene sequences of the bacterial isolates harbouring $c b b L$ form IC gene. All seven $c b b L$ positive bacterial isolates grouped with Bacillus species. Four isolates, one from each saline soil and two from agricultural soil were related to the Bacillus firmus. Two 
isolates from AS showed a very high homology (99\%) with $B$. vireti whereas one isolate was related (99\%) to $B$. horikoshii. Apparently, only a very limited diversity could be isolated using the single AT-medium under aerobic conditions without ascorbate.

\section{Diversity indices and community structure of $c b b L / 16 S$ rRNA gene libraries}

The parametric (Shannon and Simpson's diversity indices) and non parametric (Chao and ACE) diversity indices (Table 2) indicated that the diversity of $c b b L$ and $16 \mathrm{~S}$ rRNA gene clone libraries of AS differed from SS1 and SS2 soil clone libraries. In $16 \mathrm{~S}$ rRNA gene libraries the shared OTUs between three soils increased significantly on decreasing the similarity cut-off. This pattern was also evident from the $c b b L$-gene sequence analysis. The rarefaction curve of form IC $c b b L$-gene sequences (distance $=0.05)$ did not reach an asymptote in AS clone library whereas rarefaction curves reached near saturation in SS1 \& SS2 clone libraries (Additional file 6: Figure S4a). Rarefaction curves for 16S rRNA gene libraries reached near an asymptote for SS1 and SS2 saline soils at the estimated phylum level $80 \%$ (Additional file 6: Figure S4b). The agricultural soil gene library represented non asymptotic curve at phylum level $(80 \%)$ as well as at the species level (98\%) similarity cut-off. In general, the bacterial species richness in agricultural soil was greater than saline soils as indicated by the inclines in rarefaction curves.

The lack of substantial overlap between soil clone libraries suggests that bacterial communities were unique to each soil habitat. This observation was statistically supported by using LIBSHUFF ( $P=0.001$ for the average pairwise comparison for three sites), suggested that the bacterial communities retrieved from $c b b L$ and $16 \mathrm{~S}$ rRNA analysis were significantly different from one another across the sites (Additional file 7: Figure S5). The difference between homologous and heterologous coverage curves was determined by distribution of $\Delta \mathrm{C}$ as a function of evolutionary distance. Our results showed significant difference between libraries with considerable $\Delta \mathrm{C}$ values at $\mathrm{D}$ below 0.2 (Additional file 7: Figure S5). This result suggests that differences were between closely related sequences. This conclusion was also supported by the phylogenetic trees in which the sequences from different clone libraries often group near each other but were rarely identical. We employed phylogenetic tree based comparisons, the UniFrac metric, and phylogenetic $P$-test to $c b b L$ and $16 \mathrm{~S}$ rRNA clone libraries. Weighted UniFrac environmental clustering analysis indicated that the assemblages of bacterial sequences in agricultural soil were marginally differentiated from those found in the saline soils (UniFrac $P<=0.03$ ). To determine whether the samples clustered in two dimensional spaces, PCA was applied to UniFrac metric. The ordination diagram (Figure 4a) of $c b b L$ clone libraries revealed that strongest variation in the data set was between agricultural soil and saline soils as they were separated on first axis of ordination diagram, which explains high percentage of total variation (55.51\%). In case of $16 \mathrm{~S}$ rRNA gene clone libraries, the first axis separated agricultural and saline soils which explain total community variability $(57.78 \%)$ among three sample sites (Figure 4b).

\section{Discussion}

The study of microbial diversity is crucial for the understanding of structure, function, and evolution of biological communities in order to effectively link community structure and function. We constructed multiple clone libraries for each gene ( $c b b L$ form IC, IA and $16 \mathrm{~S}$ rRNA) from agricultural and saline soils, which were further analyzed. Form IC was highly diverse in all clone libraries while form IA could only be amplified from the high saline soil (SS2) clone library (Table 3). This is in accordance with the previous work reported by Nanba et al. (2004), Tolli \& King (2005) and Selesi et al. (2005) [14,24,33]. They also found form IC cbbL sequences almost exclusively dominant in various terrestrial (agroecosystem, pine forest) systems and noted that form IA was less diverse than form IC.

This study targeted functional and phylogenetic markers together in order to reveal the metabolic potentialities of the chemolithoautotrophic bacteria at three different soil habitats. Comparison of microbial populations between different soil habitats includes diversity estimation based on the expected number of OTUs. For the determination of relative diversity captured from each soil sample, both parametric (Shannon and Simpson's diversity indices) and non parametric (Chao and $\mathrm{ACE})$ diversity indices were calculated. Each diversity index is associated with the specific biases. The Shannon index takes into account consistency of species abundance in OTUs, while the Simpson's index is sensitive to abundant OTUs [36]. Chao richness is based on singletons and doubletons [37], while ACE is based on the distribution of abundant $(\geq 10)$ and rare $(\leq 10)$ species. A higher bacterial diversity was observed in the agricultural soil in comparison to the saline barren soils as revealed by Shannon and Simpson diversity indices and other non parametric indices (Table 2). This suggests that the autotrophic bacterial distribution is likely to respond to different environmental variables such as $\mathrm{pH}$, salinity, organic carbon and nitrogen concentrations etc. and the dominant populations are selected in response to changes in these variables. The soil carbon and sulphur content appears to be the major determinants of microbial community structure and function in the soil 
Table 2 Biodiversity and predicted richness of the cbbL and 16S rRNA gene sequences

\begin{tabular}{|c|c|c|c|c|c|c|c|c|c|}
\hline Genes & No of clones & Coverage (\%) & Evenness $(\mathrm{J})$ & Shannon Weiner $(\mathrm{H})$ & Simpson (1-D) & Sobs $^{1}$ (OTU) & Chao & ACE & No of Singletons \\
\hline \multicolumn{10}{|c|}{$c b b L$ form IC } \\
\hline AS & 141 & 83 & 0.92 & 3.7 & 0.98 & 58 & 71.8 & 87.2 & 24 \\
\hline SS1 & 99 & 91 & 0.92 & 3.2 & 0.96 & 32 & 34.3 & 37.6 & 8 \\
\hline SS2 & 103 & 91 & 0.94 & 3.5 & 0.97 & 40 & 43.6 & 43.8 & 9 \\
\hline \multicolumn{10}{|c|}{$c b b L$ form IA } \\
\hline SS2 & 28 & 82 & 0.58 & 1.2 & 0.55 & 8 & 11.3 & 16.8 & 5 \\
\hline \multicolumn{10}{|c|}{$16 \mathrm{~S}$ rRNA } \\
\hline AS & 147 & 33 & 0.92 & 4.3 & 0.98 & 109 & 584.3 & 4626.3 & 98 \\
\hline SS1 & 97 & 56 & 0.92 & 3.7 & 0.97 & 55 & 206.5 & 553.5 & 41 \\
\hline SS2 & 85 & 36 & 0.93 & 3.9 & 0.97 & 63 & 311.5 & 1278.9 & 53 \\
\hline
\end{tabular}

${ }^{1}$ OTUs for $c b b L$-gene clone libraries were determined at a 0.05 distance cut-off and OTUs for $16 \mathrm{~S}$ rRNA clone libraries were determined at a 0.02 cut-off using the MOTHUR program. The Coverage, Shannon-Weiner $(\mathrm{H})$, Simpson (1-D), Evenness (J) indices and Chao \& ACE richness estimators were calculated using the OTU data.

samples. But it is difficult to ascertain which particular environmental variables are driving the observed pattern of biological diversity as many of the soil and environmental characteristics are interrelated. Environmental stability is important to the development and maintenance of biodiversity [38]. Stable environments are thought to support a higher degree of organisation, more complex food webs, more niches, and ultimately more species [39]. Our data is in agreement with these assumptions as barren coastal saline soil ecosystem does not remain stable because of tidal influx thus representing less diverse ecosystem as compared to more stable agroecosystem.

LIBSHUFF analysis of $c b b L$ and 16S rRNA clone libraries verified a large degree of variability in agricultural and saline soils in all pairs of reciprocal comparisons. The differential community structure and membership in agricultural soil as compared to the saline soils were in agreement with our expectations. A change in the community composition with increase in salinity was evident at the phylum level. Microorganisms adapt to the altered salinity or they are replaced by microorganisms adapted to the changed conditions [40]. The replacement mechanism appears to operate at the phylum level, as changes of major groups were observed with increased salinity. However, at micro diversity level the gradual evolution and adaptation might take place (Figure 3) [41]. The analysis of OTUs shared between three soils revealed that bacterial communities from both the saline soils were more similar than that of agriculture soil as depicted by the overlap in Venn diagram of $c b b L$ and 16S rRNA gene clone libraries between the communities at species level cut-off (Additional file 8: Figure S6). Multiple clones from the saline soil libraries clustered together and were closely related as revealed by Lineage specific analysis in UniFrac. (a)

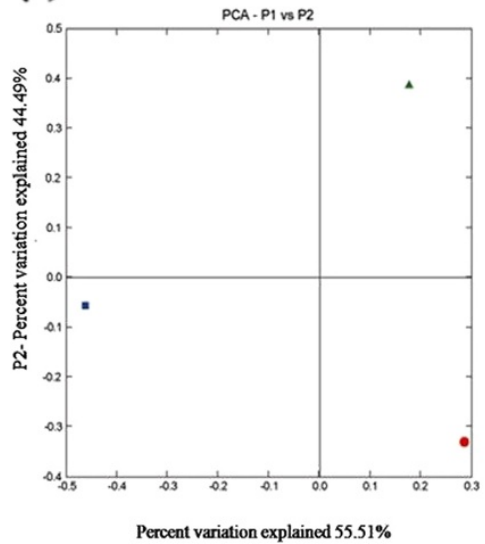

(b)

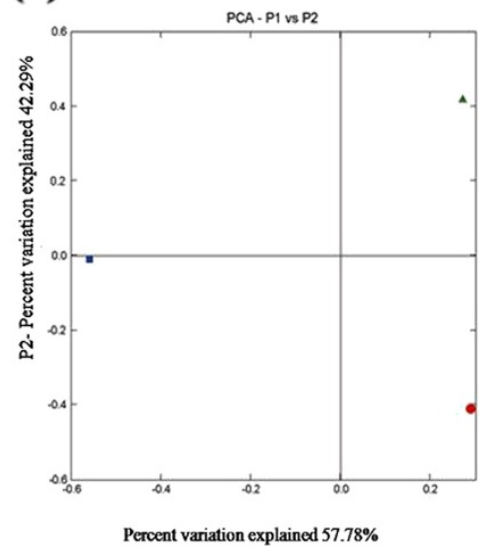

Figure 4 UniFrac PCA of $c b b L$ and 16S rRNA clone libraries. The ordination plots for the first two dimensions to show the relationship between agricultural and the saline soils for (a) cbbL and (b) 165 rRNA gene assemblages. Agricultural soil (AS) is represented by square and saline soils is represented by diamond (SS1) and circle (SS2). Each axis indicates the fraction of the variance in the data that the axis accounts for. 
Table 3 Oligonucleotide primers used for PCR amplification of $c b b L$ and 16S rRNA genes

\begin{tabular}{|c|c|c|c|c|c|c|}
\hline \multirow[t]{2}{*}{ Primer } & \multirow{2}{*}{$\begin{array}{l}\text { Position } \\
\text { (nt) }\end{array}$} & \multirow[t]{2}{*}{ Primer sequence $\left(5^{\prime}-3^{\prime}\right)$} & \multirow[t]{2}{*}{ Reference } & \multicolumn{3}{|c|}{ PCR amplification ${ }^{1}$} \\
\hline & & & & AS & SS1 & SS2 \\
\hline$c b b L R 1 F$ & $634-651$ & AAGGAYGACGAGAACATC & Selesi et al., 2005 [24] & + & + & + \\
\hline$c b b L R 1 R$ & $1435-1454$ & TCGGTCGGSGTGTAGTTGAA & & & & \\
\hline$c b b L G 1 F$ & $397-416$ & GGCAACGTGTTCGGSTTCAA & Selesi et al., 2005 [24] & - & - & - \\
\hline$c b b L G 1 R$ & $1413-1433$ & TTGATCTCTTTCCACGTTTCC & & & & \\
\hline RublgF & $571-590$ & GAYTTCACCAARGAYGAYGA & Spiridonova et al., 2004 [34] & - & - & + \\
\hline RublgR & 1363-1382 & TCRAACTTGATYTCYTTCCA & & & & \\
\hline $27 \mathrm{~F}$ & $27-46$ & AGAGTTTGATCMTGGCTCAG & Lane, 1991 [35] & + & + & + \\
\hline $1492 \mathrm{R}$ & $1471-1492$ & TACGGYTACCTTGTTACGACT & & & & \\
\hline
\end{tabular}

${ }^{1}$ Positive PCR amplification (+), no PCR amplification (-) for the targeted primers in three soil samples.

Form IC sequences were affiliated to Alpha-, Betaand Gammaproteobacteria for which chemolithotrophy and/or sulphur metabolism is a major mode of energy generation. In the composite tree, molecular phylogenetic analysis of $c b b L$ clone libraries demonstrated the presence of six different novel monophyletic lineages of $c b b L$ harbouring chemolithoautotrophic bacteria residing in the agroecosystem and saline soil clone libraries (Figure 2). These $c b b L$ genes had a low sequence similarity with $c b b L$-types from known organisms, which indicates the sources of these $c b b L$ genes may be yet unknown and uncultured autotrophic bacteria. The $c b b L$ sequences fall into 15 clusters; one cluster AS site specific, five clusters SS1 \& SS2 site specific and nine clusters having $c b b L$-gene sequences obtained from all three sampling sites. The ubiquitous distribution of majority of the phylotypes (nine mix clades) in the agroecosystem and saline soil clone libraries suggest a possible large scale distribution of several closely related chemolithotrophs. However, the possibility of high degree of sequence conservation and horizontal gene transfer in $\mathrm{RuBisCO}$ gene has limited the inference about taxonomic identity of closely related clones [19]. The saline soils phylotypes were assigned to some recognized genera like Nitrosospira, Paracoccus, Rhodobacter, Salinisphaera, and many uncultured clones from differently managed agricultural systems, contaminated aquifers and deltaic mobile sediments. These sequences from saline soil clone libraries mostly belong to Alpha- and Betaproteobacteria. The other important members of chemolithoautotrophic community in saline soils were Gammaproteobacterial autotrophs which were found predominantly in saline soil. The Gammaproteobacteria are previously known to be dominated by obligate haloalkaliphiles, for example, cluster 15 has sequences related to the genus Salinisphaera which are halophilic, aerobic, facultatively chemolithoautotrophic bacteria oxidizing $\mathrm{CO}$ and thiosulphate [42]. Some sequences from saline soil were related to nitrifying photoautotrophic purple non sulphur bacterium Rhodobacter and denitrifying bacterium Paracoccus. One phylotype was related to the Aurantimonas bacterium which is facultative lithotrophic marine manganese oxidizing bacteria. The agricultural clone library phylotypes tightly clustered with different genera of Alphaproteobacteria and Betaproteobacteria like Rhizobium, Bradyrhizobium, Xanthobacter, Beijerinckia, Sulfobacillus, Oligotropha and uncultured bacterial clones from grassland soils [26] and arid soils. Bradyrhizobium japonicum is a facultative chemolithoautotroph and utilizes thiosulphate and $\mathrm{H}_{2}$ as an electron donor and $\mathrm{CO}_{2}$ as a carbon source [43]. In cluster 10 three phylotypes from AS and one from SS1 clone libraries were related to Sulfobacillus acidophilus (sulphide oxidizing bacteria) and Mycobacterium of phylum Actinobacteria. The form IC sequences in the agroecosystem library suggest a dominance of the facultative chemolithotrophic community like $\mathrm{CO} \&$ hydrogen oxidizing, nitrogen fixing, and plant growth promoting bacteria. None of the sequences cluster closely with Nitrosospira clade, this may be due to the low abundance of ammonia oxidizers or PCR and DNA extraction biases. The agricultural soil being sulphur poor system does not significantly support the sulphur/ sulphide oxidizing bacterial populations.

All the $c b b L$ positive cultured isolates were closely related to different species of the genus Bacillus. A RuBisCO like protein (RLP), form IV RuBisCO was previously isolated and studied from B. subtilis and this RLP is involved in methionine pathway [44]. However, the form IC gene sequences from the isolates in this study are different from the form IV RLP gene $y k r W$ of $B$. subtilis. Recent studies suggested that RLP and photosynthetic RuBisCO might have evolved from the same ancestral protein [45]. Presence of form IC genes in cultured Bacillus sp. was also reported by Selesi et al. (2005) [24]. But a clear proof, whether the Bacillus isolates are completely functional autotrophs, is not yet documented. Further analysis of evolutionary and functional relationships 
between RLPs and RuBisCO may explain the presence of these form IC genes in Bacillus.

The amplification of form IA $c b b L$ genes in SS2 soil only by Spiridonova et al. (2004) [34] primers proves the primer selectivity bias. This could be supported by suppression of autotrophic bacterial growth by readily available carbon sources in case of agricultural soil [46,47]. Role of variation in other physico-chemical properties between different sites on form IA gene diversity also cannot be underestimated. In our study, most of form IA clone sequences did not cluster closely with the sequences from known sulphide oxidizing lithotrophs. This reflects that limited attention has been paid to the role of lithoautotrophs in coastal saline environments. Further isolation attempts using a variety of different media are necessary to isolate this mostly unrevealed diversity in these soils.

The 16S rRNA gene sequence analysis was aimed at providing further information about the total bacterial communities. If $16 \mathrm{~S}$ rRNA gene sequences were more than $95 \%$ similar to that of known autotrophic bacteria that genus is recognized for some form of chemolithoautotrophy and photoautotrophy [48]. Sequences inferred to be from potential $\mathrm{CO}_{2}$ fixing chemolithotrophs from groups Alpha- and Betaproteobacteria were highly abundant in the agricultural soil whereas Gammaproteobacteria, Deltaproteobacteria, Actinobacteria and phototrophic Chloroflexi dominated saline soils. Among the Betaproteobacteria two OTUs (22 clones, AS) were very closely related to Limnobacter thiooxidans (99\%), which can grow chemolithoheterotrophically by oxidation of thiosulphate to sulphate [49]. One phylotype was related (96\%) to Azohydromonas australica- nitrogen and hydrogen utilizing bacteria [50]. Two OTUs from AS clone library belonged to the phylum Nitrospira, which are facultative chemolithoautotrophic nitrite oxidizing bacteria [51]. We also obtained one phylotype from AS clone library related to the Cyanobacteria, an oxygen evolving and chlorophyll containing photosynthetic bacterium. Our agricultural clone libraries did not suggest an abundance of nitrite-oxidizing Nitrospira and phototrophic Cyanobacteria in the soil, a few sequences were identified and more may be present because the rarefaction curves (Additional file 6: Figure S4b) did not reach an asymptote. The Gammaproteobacteria sequences in SS2 clone library were related to the phototrophic Ectothiorhodospira, an alkaliphilic and halophilic purple sulphur bacterium from soda lake [52]. The phylotype HSS148 was distantly related (88\%) to the chemolithotroph Thioalkalivibrio, which oxidizes sulphide or thiosulphate with molecular oxygen. Nine OTUs from Deltaproteobacteria (SS1 clone library) fell into the order Desulfovibrionales, which oxidizes reduced sulphur compounds using a variety of electron acceptors. The light penetration through soil is minimal [53] however, the presence of Chloroflexi (filamentous anoxygenic phototrophs) in deeper soil layers (0 to $10 \mathrm{~cm}$ ) was observed in all three soil samples. This can be justified by the fact that light of higher wavelengths has the potential to penetrate deeper into the soil [54], which are used by the Chloroflexi [27].

Many of the sequences from saline soils have been previously reported from different saline environments, and the current study added significantly to the genetic pool of extreme and normal terrestrial habitats. The diversity and composition of the bacterial community along the three soil habitats varied with increase in salinity (Figure 3 ). The change in the relative proportion of the Betaproteobacteria from agricultural to saline soil habitats is particularly more apparent. Wu et al. (2006) [40] reported that with increasing salinity, the relative abundance of Betaproteobacteria decreases while that of Alpha- and Gammaproteobacteria increases. The low salinity of agricultural soil may, therefore, explain the high Betaproteobacteria diversity in AS clone library. The relative abundance of the Alpha- and Gammaproteobacteria does not show any systematic change. Alphaproteobacteria were abundant in AS clone library and Gammaproteobacteria were abundant in the saline soil clone libraries (Figure 3). Hansel et al. (2003) [55] showed the inverse relationship between carbon availability and abundance of Acidobacteria. However, the Acidobacteria group in our study did not show such relationship. The Acidobacteria sequences retrieved from the poor carbon saline soils was only $0.5 \%$, but they were abundant (14.6\%) in agricultural soil. The possible explanation for this may be the difference in other physico-chemical properties of the soils. For example, an inverse relationship between Acidobacteria diversity abundance and soil $\mathrm{pH}$ has also been previously reported [56]. Firmicutes related sequences were more abundant in saline soils in comparison to the agricultural soil. This predominance of Firmicutes related sequences in saline soils is consistent with the previous studies. For example, the Firmicutes are absent in a number of hypersaline environments $[57,58]$ but abundant in low salinity environments such as deep sea sediments [59]. Chloroflexi sequences were present at each of the three sites, however, they were most abundant at barren saline soils. Chloroflexi groups are the potential phototrophs and were abundant in barren soils [25]. This can be speculated as the saline soils provide open areas of exposed soil that can favour diverse photoautotrophic microbes $[60,61]$.

\section{Conclusions}

The four $c b b L$ libraries studied in this work demonstrated the presence of highly diversified and partially unique $c b b L$ sequences, which could belong to the 
possibly yet unknown potent $\mathrm{CO}_{2}$-fixing bacteria. The $c b b L$ form IA gene containing sulphide-oxidizing chemolithotrophs were found only in saline soil SS2 clone library, thus giving the indication of sulphide availability in this soil sample. Barren saline soils favoured diverse photoautotrophic (Chloroflexi) and chemolithoautotrophic (Gammaproteobacteria) microbial populations. The present study provides basic knowledge about the occurrence of a specific functional bacterial diversity as well as autotrophic potential of bacteria for $\mathrm{CO}_{2}$-fixation through the $\mathrm{RuBisCO}$ pathway in saline coastal soils. Alternative possible modes and pathways of $\mathrm{CO}_{2}$-fixation were not evaluated in this survey but cannot be excluded. However, it will require further investigation including 'metaproteomics' [62] which can directly link the microbial community composition to function. Identification of microbial proteins of a given habitat along with their phylogenetic affiliations will provide more comprehensive knowledge of metabolic activities occurring in microbial communities and the possible role of microbial diversity in biogeochemical processes. A better understanding of the resident bacterial communities and their functionalities in the saline barren soils should shed light on the role of barren saline soil as a possible $\mathrm{CO}_{2}$ sink.

\section{Methods}

\section{Site description and sampling}

The study was conducted on soil samples of the coastal area of Gujarat, India. Two barren sites and one agricultural field were selected along the sea coast facing the Arabian Sea. Soil samples from the depth of 0 to $10 \mathrm{~cm}$ were collected in February 2009. All sampling sites were far away from each other. The three sampling sites were designated as (i) SS1- saline soil samples collected from

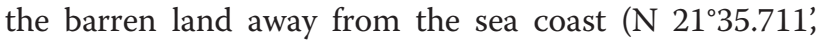
E $72^{\circ} 16.875^{\prime}$ ); (ii) SS2- saline soil samples collected

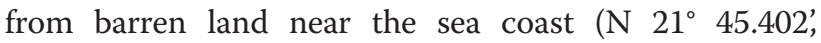
E $72^{\circ} 14.156^{\prime}$ ); (iii) AS- soil samples collected from the

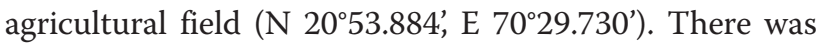
no crop in the agricultural field at the time of sample collection. However, farmers grow cotton and groundnut regularly in this field. From each site, soil samples were collected from two different transects and transported to the laboratory in sterile plastic bags. Soil samples were passed through $2 \mathrm{~mm}$ pore size sieve to remove rocks and plant materials. Serial dilutions of soil samples were prepared and plated on AT media (Additional file 9: Table S2) for bacterial isolation. DNA extraction was performed immediately from soil samples and the samples were frozen at $-20^{\circ} \mathrm{C}$ for further processing. The $\mathrm{pH}$ and salinity were measured using the Seven Easy $\mathrm{pH}$ and Conductivity meter (Mettler-Toledo AG, Switzerland) and total soil organic carbon was analyzed by Liqui
TOC (Elementar, Germany). CHNS analyzer (Perkin Elmer series ii, 2400) was used for the determination of total carbon, nitrogen and sulphur contents.

\section{Isolation of bacterial strains}

One gram of each soil sample was mixed with $9 \mathrm{~mL}$ of normal saline and homogenized for 15 minutes for isolation of $c b b L$ gene containing bacterial isolates from the soils. The soil suspension was serially diluted with normal saline to a factor of $10^{-6}$. Aliquots $(100 \mu \mathrm{L})$ were spread on AT medium (used for isolation and cultivation of purple non sulphur bacteria) and incubated for three days at $30^{\circ} \mathrm{C}$. AT medium [63] was used with some modifications i.e. sodium ascorbate was excluded from the medium and aerobic conditions were used for incubation (Additional file 9: Table S2). Twenty-two morphologically different isolates obtained from three soil samples were streaked on the AT media and incubated for three days at $30^{\circ} \mathrm{C}$.

\section{Amplification and sequencing of $c b b L$ and $16 \mathrm{~S}$ rRNA genes from bacterial isolates}

Single colonies from bacterial isolates were inoculated in $5 \mathrm{~mL}$ liquid AT medium and incubated at $30^{\circ} \mathrm{C}$ for 3 days. The cells were centrifuged and used for DNA extraction by Miniprep method [64]. CbbL and 16S rRNA genes were amplified using their respective primers and the PCR conditions (Table 3). The amplified and purified PCR products were dried and sent for sequencing (Macrogen Inc., South Korea).

\section{DNA extraction from soil samples}

Genomic DNA was extracted from $0.5 \mathrm{~g}$ of soil (from two transects per site) using the fast DNA spin kit for soil (MP Biomedicals, USA) according to the manufacturer's protocol. To disrupt the cells, the mixture of ceramic and silica beads provided in the kit and two pulses of $30 \mathrm{~s}$ and $20 \mathrm{~s}$ at speed of 5.5 of the fast prep bead beating instrument were applied. After extraction DNA was quantified and visualized by ethidium bromide-UV detection on an agarose gel.

\section{Amplification and cloning of $c b b L$ and 16S rRNA genes from soil metagenome}

The $c b b L$ (form IA and IC) and 16S rRNA genes were PCR amplified from total DNA extracted from all the soil samples using same primer sets and PCR conditions as described for bacterial isolates (Table 3). The amplified expected size PCR products were gel purified using the QIAquick gel extraction kit (Qiagen, Hilden, Germany). The purified PCR products were cloned using the TOPO TA cloning kit (Invitrogen, USA) according to the manufacturer's instructions. The multiple clone libraries for each amplified gene from the soil samples 
were constructed separately. From each clone library, clones were screened, selected randomly and analyzed for the plasmid containing insert by using the vector specific primers M13F and M13R. The plasmids harbouring the correct size inserts were extracted using alkaline lysis Mini prep method [65] and purified by RNase treatment followed by purification with phenol, chloroform and isoamyl alcohol. The purified plasmids were sent for sequencing to Macrogen Inc. (South Korea). Plasmids were sequenced with the vector specific primers M13F and M13R resulting in sequence lengths of $\approx 1500 \mathrm{bp}$ ( $16 \mathrm{~S}$ rRNA genes), $\approx 800 \mathrm{bp}$ (form IA and form IC $c b b L$ genes).

\section{Alignment and phylogenetic analysis}

All sequences were examined for chimeras using the Bellerophon tool [66] with default settings. Seventy five putative chimeric artifacts were removed from further analysis. The BLASTn program was used for retrieval of most similar sequences from GenBank [67]. The 16S rRNA gene sequences were also compared to the current database at the Ribosomal Database Project (RDP) using the RDP sequence match tool [68]. The 16S rRNA gene sequences were assigned to the phylogenetic groups by using RDP classifier [68]. Multiple sequence alignment was performed with Clustal X [69]. Phylogenetic analysis of the $c b b L$ and $16 \mathrm{~S}$ rRNA gene sequences was performed based on the representative OTU (operational taxonomic unit) sequences generated from the Mothur program [36]. Neighbour joining trees for $c b b L$ and 16S rRNA nucleotide sequences were constructed by MEGA v.4 with Jukes-Cantor correction model of distance analysis [70]. Bootstrap analysis (1000 replicates) was conducted to test the reliability of phylogenetic tree topology.

\section{OTU determination and diversity estimation}

We used a similarity cut-off of 95\% [16] for $c b b L$ and 98\% [71] for 16S rRNA nucleotide similarity to define an OTU (phylotype) by using Mothur. It uses the furthest neighbour method to assort similar sequences into groups at arbitrary levels of taxonomic similarity. Rarefaction curves, richness estimators and diversity indices were determined with Mothur [36]. Distance matrices were calculated by using the DNADIST program within the PHYLIP software package [72]. We used both the Shannon and Simpson diversity indices and Chao, ACE richness estimators calculated by Mothur to estimate microbial diversity and richness. Percentage of coverage was calculated by Good's method [73] using the formula $\mathrm{C}=[1-(\mathrm{n} / \mathrm{N})] \times 100$, where $\mathrm{n}$ is the number of OTUs in a sample represented by one clone (singletons) and $\mathrm{N}$ is the total number of sequences in that sample.

\section{Environmental clustering and comparison of $c b b L / 16 \mathrm{~S}$ rRNA clone libraries}

The differentiation in $c b b L / 16 \mathrm{~S}$ rRNA clone libraries was analyzed by comparing the coverage levels of the samples, similarities of community membership and the community structure by LIBSHUFF program [74]. It compares homologous and heterologous coverage curves by using the integral form of the Cramer-von Mises statistics and performs multiple pairwise comparisons among a set of libraries. Phylogenetic tree based analysis of community diversity was performed using the UniFrac significance test and the $P$ test within UniFrac $[75,76]$. The rooted phylogenetic tree generated in MEGA along with the environmental labels, was imported into UniFrac. PCA and $P$ test analysis was performed within the UniFrac online suite of tools. The $P$ test assesses trees for distribution of sequences within the clone libraries according to the environment [77]. All $P$ tests reported were also corrected for multiple comparisons (Bonferonni correction).

\section{Nucleotide sequence accession numbers}

The sequences determined in this study have been submitted to GenBank under the accession numbers [GenBank: HQ397346-HQ397353] (form IA $c b b L$ sequences from environmental clones), [GenBank: HQ397235HQ397345, JN202495-JN202546] (form IC $c b b L$ sequences from environmental clones), [GenBank: HQ397354-HQ397580] (16S rRNA gene sequences from environmental clones), [GenBank: HQ397588-HQ397594] (form IC $c b b L$ sequences from isolates) and [GenBank: HQ397581-HQ397587] (16S rRNA gene sequences from isolates). Representative clone sequences for each OTU from the $c b b L$ and $16 \mathrm{~S}$ rRNA gene libraries were deposited.

\section{Additional files}

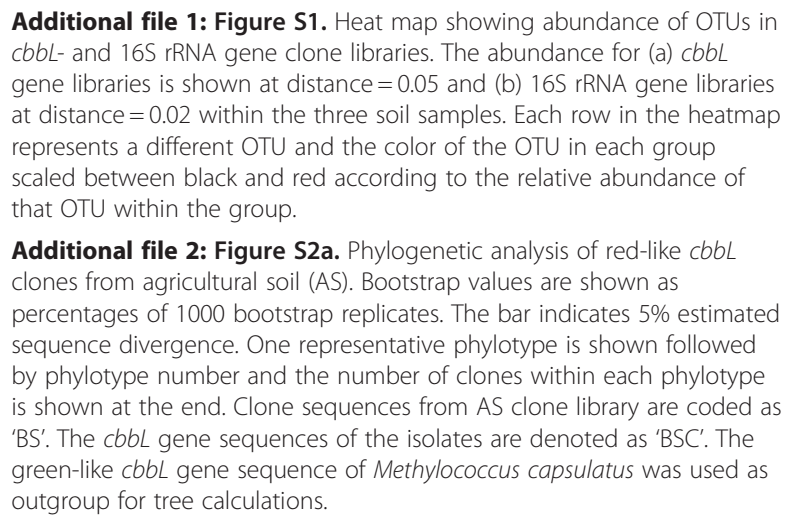

Additional file 1: Figure S1. Heat map showing abundance of OTUs in cbbL- and 165 rRNA gene clone libraries. The abundance for (a) cbbL gene libraries is shown at distance $=0.05$ and (b) $16 \mathrm{~S}$ rRNA gene libraries at distance $=0.02$ within the three soil samples. Each row in the heatmap represents a different OTU and the color of the OTU in each group scaled between black and red according to the relative abundance of that OTU within the group.

Additional file 2: Figure S2a. Phylogenetic analysis of red-like $c b b L$ clones from agricultural soil (AS). Bootstrap values are shown as percentages of 1000 bootstrap replicates. The bar indicates $5 \%$ estimated sequence divergence. One representative phylotype is shown followed by phylotype number and the number of clones within each phylotype is shown at the end. Clone sequences from AS clone library are coded as 'BS'. The $c b b L$ gene sequences of the isolates are denoted as 'BSC'. The green-like cbbl gene sequence of Methylococcus capsulatus was used as outgroup for tree calculations.

Additional file 3: Figure S2b. Phylogenetic analysis of red-like $c b b L$ clones from saline soils (SS1 \& SS2) clone libraries. Bootstrap values are shown as percentages of 1000 bootstrap replicates. The bar indicates $5 \%$ 
estimated sequence divergence. One representative phylotype is shown followed by phylotype number and the number of clones within each phylotype is shown at the end. Clone sequences are coded as 'HS' (SS1) and ' $R$ ' (SS2). The cbbl gene sequences of the isolates from this study are denoted as 'HSC' and 'RSC' from SS1 and SS2 respectively. The green-like $c b b l$ gene sequence of Methylococcus capsulatus was used as outgroup for tree calculations.

Additional file 4: Table S1. Taxonomic distribution of 165 rDNA clones. The OTUs were generated using a $16 \mathrm{~S}$ rDNA percent identity value of $98 \%$.

Additional file 5: Figure S3. Neighbour joining phylogenetic tree of 165 rRNA nucleotide sequences from bacterial isolates. This phylogenetic tree reflecting the relationships of red-like $c b b L$ harbouring bacterial isolates with closely related known isolates. 16S rRNA gene sequences of the isolates from this study were denoted as 'BSCS' from agricultural soil (AS), 'HSCS' from saline soil (SS1) and 'RSCS' from saline soil (SS2). Methanothermobacter autotrophicus was used as outgroup. The bar indicates $5 \%$ estimated sequence divergence.

Additional file 6: Figure S4. Number of OTUs as a function of total number of sequences. Rarefaction curves for (a) $c b b L$ gene libraries at 0.05 distance cut-off and (b) $16 \mathrm{~S}$ rRNA gene clone libraries at a phylum level distance (0.20) for the expected no of OTUs. Bacterial richness in agricultural soil (AS) and saline soils (SS1 \& SS2) is indicated by slopes of the rarefaction curves.

Additional file 7: Figure S5. Results of selected LIBSHUFF comparisons. (I) $16 \mathrm{~S}$ rRNA libraries (a1) AS (X) to SS1 (Y), (a2) libraries AS (X) to SS2 (Y) and (a3) libraries SS1 (X) to SS2 (Y). (II) CbbL libraries (b1) ASC (X) to SS1C (Y), (b2) libraries ASC (X) to SSC2 ( $Y$ ) and (b3) libraries SS1C (X) to SS2C(Y). Agricultural soil is denoted as 'AS' while as saline soils are denoted as 'SS1 \& SS2'.

Additional file 8: Figure S6. Venn diagrams showing overall overlap of representative genera. Venn diagrams representing the observed overlap of OTUs for (a) cbbl gene libraries (distance $=0.05$ ) and $(b) 16 \mathrm{~S}$ rRNA gene libraries (distance $=0.02$ ). The values in the diagram represent the number of genera that were taxonomically classified.

Additional file 9: Table S2. Composition of AT media (Imhoff).

\section{Abbreviations}

OTU: Operational taxonomic unit; AS: Agricultural soil; SS1: Saline soil 1; SS2: Saline soil 2.

\section{Competing interests}

The authors declare that they have no competing interests.

\section{Authors' contributions}

BY: participated in the design of the study, carried out culture independent related experiments, bioinformatics analysis and drafted the manuscript, PS: carried out the culture dependent study, helped in bioinformatics analysis and drafted the manuscript, JK: participated in the study's design, carried out phylogenetic analysis and drafted the manuscript, BJ: conceived the study and coordination, edited the manuscript and received the funding needed to complete the research. All authors read and approved the final manuscript.

\section{Acknowledgements}

The financial support received from Council of Scientific and Industrial Research (CSIR), New Delhi (Network Project NWP-20) is thankfully acknowledged.

Received: 27 January 2012 Accepted: 6 July 2012

Published: 26 July 2012

\section{References}

1. Kelly DP, Wood AP: The chemolithotrophic prokaryotes. In Prokaryotes. Volume 2. Edited by Dworkin M. New York: Springer; 2006:441-456.

2. Campbell BJ, Engel AS, Porter ML, Takai K: The $\boldsymbol{\epsilon}$-proteobacteria: key players in sulphidic habitats. Nature Rev Microbiol 2006, 4:458-468.
3. Atomi $\mathrm{H}$ : Microbial enzymes involved in carbon dioxide fixation. J Biosci Bioeng 2002, 94(6):497-505.

4. Ellis RJ: The most abundant protein in the world. Trends Biochem Sci 1979, 4:241-244.

5. Tabita FR: Molecular and cellular regulation of autotrophic carbon dioxide fixation in microorganisms. Microbiol Rev 1988, 52:155-189.

6. Watson GMF, Yu JP, Tabita FR: Unusual ribulose 1,5-bisphosphate carboxylase/oxygenase of anoxic Archaea. J Bacteriol 1999, 181(5):1569-1575.

7. Maeda N, Kanai T, Atomi H, Imanaka T: The unique pentagonal structure of an archaeal Rubisco is essential for its high thermostability. J Biol Chem 2002, 277(35):31656-31662.

8. Kunst F, Ogasawara N, Moszer I, Albertini AM, Alloni G, Azevedo V, Bertero $M G$, Bessieres P, Bolotin A, Borchert S, et al: The complete genome sequence of the Gram-positive bacterium Bacillus subtilis. Nature 1997, 390(6657):249-256.

9. Hanson TE, Tabita FR: A ribulose-1,5-bisphosphate carboxylase/oxygenase (RubisCO)-like protein from Chlorobium tepidum that is involved with sulfur metabolism and the response to oxidative stress. Proc Natl Acad Sci USA 2001, 98(8):4397-4402.

10. Klenk HP, Clayton RA, Tomb JF, White O, Nelson KE, Ketchum KA, Dodson RJ, Gwinn M, Hickey EK, Peterson JD, et al: The complete genome sequence of the hyperthermophilic, sulphate-reducing archaeon Archaeoglobus fulgidus. Nature 1997, 390(6658):364-370.

11. Kusian $\mathrm{B}$, Bowien $\mathrm{B}$ : Organization and regulation of $\mathrm{cbb} \mathrm{CO}_{2}$ assimilation genes in autotrophic bacteria. FEMS Microbiol Rev 1997, 21(2):135-155.

12. Watson GMF, Tabita FR: Microbial ribulose 1,5-bisphosphate carboxylase/ oxygenase: A molecule for phylogenetic and enzymological investigation. FEMS Microbiol Lett 1997, 146(1):13-22.

13. Lee SN, Kim YM: Cloning and characterization of ribulose bisphosphate carboxylase gene of a carboxydobacterium, Hydrogenophaga pseudoflava DSM 1084. Mol Cells 1998, 8(5):524-529.

14. Tolli J, King GM: Diversity and structure of bacterial chemolithotrophic communities in pine forest and agroecosystem soils. Appl Environ Microbiol 2005, 71(12):8411-8418.

15. Horz HP, Yimga MT, Liesack W: Detection of methanotroph diversity on roots of submerged rice plants by molecular retrieval of $\mathrm{pmoA}, \mathrm{mmoX}$, mxaF, and 165 rRNA and ribosomal DNA, including pmoA-based terminal restriction fragment length polymorphism profiling. Appl Environ Microbiol 2001, 67(9):4177-4185.

16. Jiang L, Zheng Y, Peng X, Zhou H, Zhang C, Xiao X, Wang F: Vertical distribution and diversity of sulphate-reducing prokaryotes in the Pearl River estuarine sediments, Southern China. FEMS Microbiol Ecol 2009, 70:249-262.

17. Huegler $\mathrm{M}$, Gaertner $\mathrm{A}$, Imhoff JF: Functional genes as markers for sulfur cycling and $\mathrm{CO}_{2}$ fixation in microbial communities of hydrothermal vents of the Logatchev field. FEMS Microbiol Ecol 2010, 73(3):526-537.

18. Severin I, Acinas SG, Stal LJ: Diversity of nitrogen-fixing bacteria in cyanobacterial mats. FEMS Microbiol Ecol 2010, 73(3):514-525.

19. Delwiche CF, Palmer JD: Rampant horizontal transfer and duplication of rubisco genes in eubacteria and plastids. Mol Biol Evol 1996, 13(6):873-882.

20. Alfreider A, Vogt C, Hoffmann D, Babel W: Diversity of ribulose-1,5bisphosphate carboxylase/oxygenase large-subunit genes from groundwater and aquifer microorganisms. Microb Ecol 2003, 45(4):317-328.

21. Giri BJ, Bano N, Hollibaugh JT: Distribution of RuBisCO genotypes along a redox gradient in Mono Lake, California. Appl Environ Microbiol 2004, 70(6):3443-3448

22. van der Wielen P: Diversity of ribulose-1,5-bisphosphate carboxylase/ oxygenase large-subunit genes in the $\mathrm{MgCl} 2$-dominated deep hypersaline anoxic basin discovery. FEMS Microbiol Lett 2006, 259(2):326-331.

23. Nigro LM, King GM: Disparate distributions of chemolithotrophs containing form IA or IC large subunit genes for ribulose-1,5bisphosphate carboxylase/oxygenase in intertidal marine and littoral lake sediments. FEMS Microbiol Ecol 2007, 60(1):113-125.

24. Selesi D, Schmid M, Hartmann A: Diversity of green-like and red-like ribulose-1,5-bisphosphate carboxylase/oxygenase large-subunit genes (cbbL) in differently managed agricultural soils. Appl Environ Microbiol 2005, 71(1):175-184.

25. Freeman KR, Pescador MY, Reed SC, Costello EK, Robeson MS, Schmidt SK: Soil $\mathrm{CO}_{2}$ flux and photoautotrophic community composition in highelevation, 'barren' soil. Environ Microbiol 2009, 11(3):674-686. 
26. Videmsek U, Hagn A, Suhadolc M, Radl V, Knicker H, Schloter M, Vodnik D: Abundance and diversity of $\mathrm{CO}_{2}$-fixing bacteria in grassland soils close to natural carbon dioxide springs. Microb Ecol 2009, 58(1):1-9.

27. van der Meer MTJ, Schouten S, Bateson MM, Nubel U, Wieland A, Kuh M, de Leeuw JW, Damste JSS, Ward DM: Diel variations in carbon metabolism by green nonsulfur-like bacteria in alkaline siliceous hot spring microbial mats from Yellowstone National Park. Appl Environ Microbiol 2005, 71(7):3978-3986.

28. Cayol JL, Ollivier B, Patel BKC, Prensier G, Guezennec J, Garcia JL: Isolation and characterization of Halothermothrix orenii gen. nov., sp. nov., a halophilic, thermophilic, fermentative, strictly anaerobic bacterium. Int $\rfloor$ Syst Evol Microbiol 1994, 44:534-540.

29. Ying J-Y, Liu Z-P, Wang B-J, Dai X, Yang S-S, Liu S-J: Salegentibacter catena sp. nov., isolated from sediment of the South China Sea, and emended description of the genus Salegentibacter. Int J Syst Evol Microbiol 2007 57:219-222

30. Militon C, Boucher D, Vachelard C, Perchet G, Barra V, Troquet J, Peyretaillade E, Peyret $P$ : Bacterial community changes during bioremediation of aliphatic hydrocarbon-contaminated soil. FEMS Microbiol Ecol 2010, 74(3):669-681.

31. Navarro-Noya YE, Jan-Roblero J, González-Chávez MDC, Hernández-Gama R, Hernández-Rodríguez C: Bacterial communities associated with the rhizosphere of pioneer plants (Bahia xylopoda and Viguiera linearis) growing on heavy metals-contaminated soils. Antonie Van Leeuwenhoek 2010, 97(4):335-349.

32. Sorokin DY, van Pelt S, Tourova TP, Evtushenko LI: Nitriliruptor alkaliphilus gen. nov., sp. nov., a deep-lineage haloalkaliphilic actinobacterium from soda lakes capable of growth on aliphatic nitriles, and proposal of Nitriliruptoraceae fam. nov and Nitriliruptorales ord. nov. Int J Syst Evol Microbiol 2009, 59:248-253.

33. Nanba K, King GM, Dunfield K: Analysis of facultative lithotroph distribution and diversity on volcanic deposits by use of the large subunit of ribulose 1,5-bisphosphate carboxylase/oxygenase. Appl Environ Microbiol 2004, 70(4):2245-2253.

34. Spiridonova EM, Berg IA, Kolganova TV, Ivanovskii RN, Kuznetsov BB, Turova TP: An oligonucleotide primer system for amplification of the ribulose- 1 5-bisphosphate carboxylase/oxygenase genes of bacteria of various taxonomic groups. Mikrobiologiia 2004, 73(3):377-387.

35. Lane DJ: 16S/23S rRNA sequencing. In Nucleic acid techniques in bacterial systematics. Edited by Stackebrandt E, Goodfellow M. Chichester: Wiley; 1991:115-175

36. Schloss PD, Handelsman J: A statistical toolbox for metagenomics: assessing functional diversity in microbial communities. BMC Bioinforma 2008, 9:34-48

37. Chao A: Non-parametric estimation of the number of classes in a population. Scand J Stat 1984, 11:783-791.

38. Peck LS, Convey P, Barnes DKA: Environmental constraints on life histories in Antarctic ecosystems: tempos, timings and predictability. Biol Rev 2006 81(1):75-109.

39. Yergeau E, Newsham KK, Pearce DA, Kowalchuk GA: Patterns of bacterial diversity across a range of Antarctic terrestrial habitats. Environ Microbio 2007, 9:2670-2682

40. Wu QL, Zwart G, Schauer M: Kamst-van Agterveld MP, Hahn MW: Bacterioplankton community composition along a salinity gradient of sixteen high-mountain lakes located on the Tibetan Plateau, China. App Environ Microbiol 2006, 72(8):5478-5485.

41. Jiang $H$, Dong $H, Y u$ B, Liu X, Li Y, Ji S, Zhang CL: Microbial response to salinity change in Lake Chaka, a hypersaline lake on Tibetan plateau. Environ Microbiol 2007, 9(10):2603-2621.

42. Crespo-Medina M, Chatziefthimiou A, Cruz-Matos R, Pérez-Rodríguez I, Barkay T, Lutz RA, Starovoytov V, Vetriani C: Salinisphaera hydrothermalis sp. nov., a mesophilic, halotolerant, facultative autotrophic, thiosulfateoxidizing gammaproteobacterium from deep-sea hydrothermal vents, and emended description of the genus Salinisphaera. Int I Syst Evol Microbiol 2009, 59:1497-1503.

43. Masuda S, Eda S, Sugawara C, Mitsui H, Minamisawa K: The cbbL Gene is Required for Thiosulfate-Dependent Autotrophic Growth of Bradyrhizobium japonicum. Microbes Environ 2010, 25(3):220-223.

44. Ashida H, Saito Y, Kojima C, Kobayashi K, Ogasawara N, Yokota A: A functional link between RuBisCO-like protein of Bacillus and photosynthetic RuBisCO. Science 2003, 302(5643):286-290.
45. Ashida H, Saito Y, Nakano T, de Marsac NT, Sekowska A, Danchin A, Yokota A: RuBisCO-like proteins as the enolase enzyme in the methionine salvage pathway: functional and evolutionary relationships between RuBisCO-like proteins and photosynthetic RuBisCO. J Exp Bot 2008, 59(7):1543-1554.

46. Miltner A, Kopinke FD, Kindler R, Selesi DE, Hartmann A, Kastner M: Non-phototrophic $\mathrm{CO}_{2}$ fixation by soil microorganisms. Plant Soil 2005, 269(1-2):193-203.

47. Carney KM, Hungate BA, Drake BG, Megonigal JP: Altered soil microbial community at elevated $\mathrm{CO}_{2}$ leads to loss of soil carbon. Proc Natl Acad Sci USA 2007, 104(12):4990-4995.

48. Chaudhary A, Haack SK, Duris JW, Marsh TL: Bacterial and archaeal phylogenetic diversity of a Cold Sulfur-Rich spring on the shoreline of Lake Erie, Michigan. App/ Environ Microbiol 2009, 75(15):5025-5036.

49. Spring S, Kampfer P, Schleifer KH: Limnobacter thiooxidans gen. nov., sp. nov., a novel thiosulfate-oxidizing bacterium isolated from freshwater lake sediment. Int J Syst Evol Microbiol 2001, 51:1463-1470.

50. Coelho MRR, de Vos M, Carneiro NP, Marriel IE, Paiva E, Seldin L: Diversity of nifH gene pools in the rhizosphere of two cultivars of sorghum (Sorghum bicolor) treated with contrasting levels of nitrogen fertilizer. FEMS Microbiol Lett 2008, 279(1):15-22.

51. Luecker S, Wagner M, Maixner F, Pelletier E, Koch H, Vacherie B, Rattei T, Damste JSS, Spieck E, Le Paslier D, Daims H: A Nitrospira metagenome illuminates the physiology and evolution of globally important nitriteoxidizing bacteria. Proc Natl Acad Sci USA 2010, 107(30):13479-13484.

52. Gorlenko VM, Bryantseva IA, Rabold S, Tourova TP, Rubtsova D, Smirnova E, Thiel V, Imhoff JF: Ectothiorhodospira variabilis sp. nov., an alkaliphilic and halophilic purple sulfur bacterium from soda lakes. Int J Syst Evol Microbiol 2009, 59:658-664

53. Kasperbauer MJ, Hunt PG: Biological and photometric measurement of light transmission through soils of various colors. Botan Gaz 1988, 149(4):361-364.

54. Tester M, Morris C: The penetration of light through soil. Plant Cell Environ 1987, 10(4):281-286.

55. Hansel CM, Benner SG, Neiss J, Dohnalkova A, Kukkadapu RK, Fendorf S: Secondary mineralization pathways induced by dissimilatory iron reduction of ferrihydrite under advective flow. Geochim Cosmochim Acta 2003, 67(16):2977-2992.

56. Eichorst SA, Breznak JA, Schmidt TM: Isolation and characterization of soil bacteria that define Teniglobus gen. nov., in the phylum Acidobacteria. Appl Environ Microbiol 2007, 73(8):2708-2717.

57. Benlloch S, Lopez-Lopez A, Casamayor EO, Ovreas L, Goddard V, Daae FL, Smerdon G, Massana R, Joint I, Thingstad F, Pedros-Alio C, Rodríguez-Valera F: Prokaryotic genetic diversity throughout the salinity gradient of a coastal solar saltern. Environ Microbiol 2002, 4(6):349-360.

58. Demergasso C, Casamayor EO, Chong G, Galleguillos P, Escudero L, Pedros-Alio C: Distribution of prokaryotic genetic diversity in athalassohaline lakes of the Atacama Desert, Northern Chile. FEMS Microbiol Ecol 2004, 48(1):57-69.

59. Li LN, Kato C, Horikoshi K: Bacterial diversity in deep-sea sediments from different depths. Biodivers Conserv 1999, 8(5):659-677.

60. Casamatta DA, Johansen JR, Vis ML, Broadwater ST: Molecular and morphological characterization of ten polar and near-polar strains within the Oscillatoriales (Cyanobacteria). J Phycol 2005, 41(2):421-438.

61. Wood SA, Rueckert A, Cowan DA, Cary SC: Sources of edaphic cyanobacterial diversity in the Dry Valleys of Eastern Antarctica. ISME J 2008, 2(3):308-320.

62. Keller M, Hettich R: Environmental proteomics: a paradigm shift in characterizing microbial activities at the molecular level. Microbiol Mol Biol Rev 2009, 73(1):62-70.

63. Imhoff JF: The phototrophic alpha-Proteobacteria. In Prokaryotes. Volume 5. Edited by Dworkin M. New York: Springer; 2006:41-64.

64. Wilson K: Preparation of genomic DNA from bacteria. In Current protocols in molecular biology. Edited by Ausubel FM, Brent R, Kingston RE, Moore DD, Seidman JG, Smith JA, Struhl K. New York: Wiley; 2001. 2.4.1-2.4.2.

65. Sambrook J, Russell D: Molecular Cloning: A Laboratory Manual. 3rd edition. New York: Cold Spring Harbor Laboratory Press; 2001.

66. Huber T, Faulkner G, Hugenholtz P: Bellerophon: a program to detect chimeric sequences in multiple sequence alignments. Bioinformatics 2004, 20(14):2317-2319.

67. Altschul SF, Gish W, Miller W, Myers EW, Lipman DJ: Basic Local Alignment Search Tool. J Mol Biol 1990, 215(3):403-410 
68. Wang Q, Garrity GM, Tiedje JM, Cole JR: Naive Bayesian classifier for rapid assignment of rRNA sequences into the new bacterial taxonomy. Appl Environ Microbiol 2007, 73(16):5261-5267.

69. Thompson JD, Gibson TJ, Plewniak F, Jeanmougin F, Higgins DG: The Clustal $X$ windows interface: flexible strategies for multiple sequence alignment aided by quality analysis tools. Nucleic Acids Res 1997, 25(24):4876-4882.

70. Tamura K, Dudley J, Nei M, Kumar S: MEGA4: Molecular evolutionary genetics analysis (MEGA) software version 4.0. Mol Biol Evol 1599, 24(8):1596.

71. Fields MW, Schryver JC, Brandt CC, Yan T, Zhou JZ, Palumbo AV: Confidence intervals of similarity values determined for cloned SSU rRNA genes from environmental samples. J Microbiol Meth 2006, 65(1):144-152.

72. Felsenstein J: PHYLIP: phylogeny inference package (version 3.2). Cladistics 1989, 5:164-166.

73. Good IJ: The Population frequencies of species and the estimation of population parameters. Biometrika 1953, 40:237-264.

74. Singleton DR, Furlong MA, Rathbun SL, Whitman WB: Quantitative comparisons of $16 \mathrm{~S}$ rRNA gene sequence libraries from environmental samples. Appl Environ Microbiol 2001, 67(9):4374-4376.

75. Lozupone C, Knight R: UniFrac: a new phylogenetic method for comparing microbial communities. Appl Environ Microbiol 2005, 71(12):8228-8235.

76. Lozupone C, Hamady M, Knight R: UniFrac - An online tool for comparing microbial community diversity in a phylogenetic context. BMC Bioinforma 2006, 7:371-384.

77. Martin AP: Phylogenetic approaches for describing and comparing the diversity of microbial communities. Appl Environ Microbiol 2002, 68(8):3673-3682.

doi:10.1186/1471-2180-12-150

Cite this article as: Yousuf et al: Comparative molecular analysis of chemolithoautotrophic bacterial diversity and community structure from coastal saline soils, Gujarat, India. BMC Microbiology 2012 12:150.

\section{Submit your next manuscript to BioMed Central and take full advantage of:}

- Convenient online submission

- Thorough peer review

- No space constraints or color figure charges

- Immediate publication on acceptance

- Inclusion in PubMed, CAS, Scopus and Google Scholar

- Research which is freely available for redistribution

Submit your manuscript at www.biomedcentral.com/submit
() Biomed Central 